\title{
Public Transit Equity Analysis at Metropolitan and Local Scales: A Focus on Nine Large Cities in the US
}

\author{
Greg Phillip Griffin and Ipek Nese Sener \\ Texas A\&M Transportation Institute
}

\begin{abstract}
Recent studies on transit service through an equity lens have captured broad trends from the literature and national-level data or analyzed disaggregate data at the local level. This study integrates these methods by employing a geostatistical analysis of new transit access and income data compilations from the Environmental Protection Agency. By using a national data set, this study demonstrates a method for income-based transit equity analysis and provides results spanning nine large auto-oriented cities in the US. Results demonstrate variability among cities' transit services to low-income populations, with differing results when viewed at the regional and local levels. Regional-level analysis of transit service hides significant variation through spatial averaging, whereas the new data employed in this study demonstrates a block-group scale equity analysis that can be used on a national-scale data set. The methods used can be adapted for evaluation of transit and other modes' transportation service in areas to evaluate equity at the regional level and at the neighborhood scale while controlling for spatial autocorrelation. Transit service equity planning can be enhanced by employing local Moran's I to improve local analysis.
\end{abstract}

Keywords: Transit; equity; local Moran's I

\section{Introduction}

Public transportation serves the important role of providing affordable mobility across the social and economic spectrum, particularly for the largest cities in the United States (Forkenbrock and Sheeley 2004; Pucher 2004). Transit planners need analysis methods that balance practicality and precision to evaluate how well proposed improvements meet the needs of riders, especially those who may have limited options due to income. This study deploys a consistent data and techniques that can evaluate the relative quality of transit service to employment opportunities at a variety of geographic scales. 
The recent federal emphasis on evaluating transportation investments with performance measures provides an opportunity for transportation agencies to employ new data sources and methods to evaluate transit service (United States Congress 2012). Since this responsibility for measuring performance is most often attributed to individual transportation agencies (Fabish and Haas 2011; Ramani et al. 2011), most previous studies of transit service equity approach the problem as either a qualitative overview within a region, or as case studies with notable methodological advancements (Beyazit 2011; Delbosc and Currie 2011; Duthie, Cervenka, and Waller 2007; Forkenbrock and Schweitzer 1999; Forkenbrock and Sheeley 2004; Foth, Manaugh, and El-Geneidy 2013; Golub 2014), rather than comparing service equity details among peer agencies. Transportation agencies can analyze equity from multiple perspectives and time frames, and additional methods help improve planning for a range of equity perspectives (Duthie et al. 2007; Hay 1993; Kaplan et al. 2014; Welch and Mishra 2013).

Accessible transit service is an equity issue because buses, trains, and other transit services provide the motorized transport necessary for social inclusion and for access to jobs needed for social mobility (Boschmann and Kwan 2010; Clark and Wang 2010; Lucas 2012; Phillips and Edwards 2002; Sanchez, Stolz, and Ma 2004). This study focuses on transit equity regarding access to service, rather than including costs to individuals. This approach does not account for individual mobility needs or personal costs. This is aligned with the concept of horizontal equity, where fairness of services across income groups is considered; however, it does not consider vertical equity in the sense that disadvantaged households would pay a smaller share or receive greater services than others (Litman 2007, p. 51). Low-income populations that may not have access to a car are put at a disadvantage in competing for jobs located more than a few blocks from home, even if they are fully qualified. Slower transit services also compound challenges on low-income families who need to chain trips to stores with work and transporting children to school and other activities (Bricka 2008; Christie et al. 2011; Jain, Line, and Lyons 2011; Jiao, Moudon, and Drewnowski 2011; Sanchez et al. 2004). Transit systems are planned at the geographic scale of the region or city, but the benefits and costs of transit provision is felt at the local level. Individual routing of bus or rail service in, or around, neighborhoods of differing income status has accordingly different effects on the residents' access to jobs, goods, and services (Delbosc and Currie 2011; Foth et al. 2013; jiao et al. 2011).

This study contributes to the literature on transit equity by reviewing a relatively standard, region-level descriptive statistic of access to transit service, with a novel application of a geostatistic (through local Moran's I) that identifies significant clusters and outliers of high and low transit service access by differing populations. In addition, using a nation-wide dataset allows comparison of transit equity by region and by neighborhood. This method has the potential to identify equity issues with existing transit service early in a planning process, to help guide further analysis of potential transit infrastructure and service. Transit access can have many implications on the geography of opportunities for jobs, healthy food, cultural resources, and other human needs documented elsewhere in the urban geography literature. Access to transit affects broad aspects of people's lives, particularly those whose mobility options may 
be limited by circumstance. Improved transit data and analysis methods are valuable to help address the equity of urban transit provision, and improve the discourse of transportation planning by evaluating equity at multiple scales.

The paper begins with a brief review of the challenges of transportation equity in the United States. We then position the study in the context of our focus on large cities in the United States. Finally, we propose a geostatistical method to provide a stronger methodological bridge between the understanding of geodemographics and transit services, offering conclusions linking this study for use at the sub-national level and in other countries.

\section{Evaluating Transportation Equity}

There is little debate on the role of transportation planners and governments to provide infrastructure enabling mobility to as many people as possible, but the challenges involve the decisions involved with equitable distribution of transport resources over a finite population geography (Boarnet 2009; Litman and Brenman 2012; Martens, Golub, and Robinson 2012).

Some recent research has identified that the scale of evaluation is important. In the United States, authority for major transportation investments are frequently at the state level (Plotnick et al. 2011), yet the everyday impact of transportation on peoples' lives occurs at the regional and local levels (Bond and Kramer 2010; Bullard 2008). Appleyard and others have suggested that wealth and social status play a major role in guiding decisions concerning who's community is made more livable through certain transportation investments, suggesting normative principles based on supporting pursuit of quality of life, and care for society's most vulnerable citizens (Appleyard et al. 2014).

Transportation access is a multimodal challenge. Although transit is considered a key mode for equitable mobility, access to an automobile has been shown to significantly increase opportunities for employment (Clark and Wang 2010). However, other factors such as demographics, geographic factors, and access to multiple transportation modes affect access to employment in complicated ways, so improving the roadway network alone cannot be expected to fix all employment access problems for all people (Boschmann and Kwan 2010). The adequacy of sidewalks, affordable bike sharing systems, and other modes all play a significant role in accessing transit service (Ehrenfeucht and Loukaitou-Sideris 2010; Goodman and Cheshire 2014; Griffin and Sener 2016).

In theory, effective transportation planning that integrates social equity as a core value should help direct urban regions towards a more just transportation system. In practice, a recent review of equity objectives and measures in North American transportation plans suggests these values are not clearly integrated in the planning process (Manaugh, Badami, and El-Geneidy 2015). 
Local and regional planning bodies often face challenging choices on which aspects to focus on given resource and time constraints (Duthie et al. 2007), and the reality that adequate information may not be readily available (McCray 2009). Information needed for these analyses often comes from modeling, geographic information systems, and qualitative methods.

Evaluation of transportation user effects include methods to evaluate the ability to reach desired destinations and choices in terms of quantity and quality of transportation options, typically involving geographic information systems (GIS) and travel demand forecasting. GIS has become instrumental to integrate existing sociodemographic community data with planning scenarios developed in a modeling framework. GIS-based platforms have the particular strengths to geographically organize data for analysis of numerical data, and more recently for information gleaned from affected persons of a qualitative nature (Jones and Evans 2012; McCray and Brais 2007).

Many of these methods were developed by researchers and planners with their peers in mind, rather than providing tools understandable or usable by a wider population (Bailey and Grossardt 2009; Hanna 2000). One recent advancement to make transportation equity analysis more accessible involved the development of a proofof-concept website that arrays various regional transportation scenarios in a planning effort, vis-à-vis demographic groups such as income and race (Golub, Robinson, and Nee 2013). Although this effort provides a new method to expand the availability of information to the public with an environmental justice perspective, the authors noted it may be complicated for some users, and lead to misinterpretation. Recent research shows that advancements in transport policies regarding equity have had limited effect on equity of transit service (Golub, Marcantonio, and Sanchez 2013). This study proposes a step back from case studies, to a larger perspective of multiple large cities.

\section{United States Transit Context}

Though transportation equity is a concern over all populations and places, this study focused on the challenges of transit service in large, auto-centric cities in the United States. This emphasis combines an interest in both the unique challenges of more auto-oriented growing cities and the presence of newly-developed data. The availability of the Environmental Protection Agency's (EPA's) new Access to Jobs and Workers via Transit promotes efficient geographic analysis, while covering $88 \%$ of all transit ridership in the United States (Ramsey and Bell 2014). This emphasis seizes an opportunity to leverage new data to support equity analysis in cities with expanding and changing transit systems.

\section{United States Legal Planning Requirements}

Federal actions on civil rights began broad changes in transportation planning in the United States, but many issues related to both policy frameworks and the role of stafflevel decisions regarding equity continue (Karner and Niemeier 2013; United States 
Department of Justice 1964). In 1994, Executive Order 12898, Federal Actions to Address Environmental Justice in Minority Populations and Low-Income Populations (Clinton 1994), updated earlier guidance on Environmental Justice (United States Department of Transportation 2012). The new guidance advised transportation planners to avoid disproportionate adverse impacts on minority and low-income groups, and the research community responded with diverse solutions for improving transportation equity. However, most of the methods address only automobile traffic, either regarding network efficiency (Duthie and Waller 2008), tolling impacts (Plotnick et al. 2011; Ungemah 2007), or negative impacts such as air and noise pollution (Forkenbrock and Schweitzer 1999). Metropolitan planning organizations (e.g., Capital Area Metropolitan Planning Organization 2010) and states (e.g., Cambridge Systematics and Akin, Gump, Strauss, Hauer and Field 2002) have considered environmental justice criteria as part of the multimodal project prioritization, but no known studies have systematically analyzed transit services offered in the United States from an environmental justice perspective.

\section{Focus on Nine Large Cities in the United States}

This study focuses on large cities in the US that have not retained a robust transit system over several generations. New York City, Boston, Massachusetts, and, to some extent, Washington, DC, were largely developed before popularization of the automobile, and built out rail and bus transit systems concurrently with development. In terms of equity, more challenges are anticipated in cities developing in the midst of the challenges of suburban dispersal, limited transit funding, and growth in population and employment. An additional requirement for this study is the availability of transit operation data combined with income data for equity analysis, which is described later. The following nine cities meet these criteria, and their regions comprise the focus of this study: Atlanta, GA; Austin, TX; Dallas, TX; Denver, CO; Houston, TX; Indianapolis, IN; Los Angeles, CA; Seattle, WA; and San Diego, CA. Whereas the aim of the present research is focused on an empirical and methodological approach to equity, the cultural and political contexts of these cities and their states vary widely and are expected to be among the drivers of transit planning and service outcomes (Grengs 2002). The known similarities and contextual differences between the cities motivates our multiple case study approach, which facilitates understanding of the differences in local issues, but also supports the validity and generalizability of this study's conclusions (Chmiliar 2010; Schlossberg 2001).

Each of these large cities of focus in this study varies in its size, density, and transit service. Table 1 includes their basic characteristics based on the 2012 National Transit Database (NTD) (Federal Transit Administration 2014), with calculations performed by the authors. Whereas Atlanta is similar to the other cities in terms of its service area and population, it has a 96-mile heavy rail system with almost double the annual passenger miles of its bus system. Indianapolis has the lowest passenger kilometers per capita, with a straightforward bus system. Service area population densities vary from that of the urbanized area because transit services for the primary transit agency may extend well past municipal boundaries or can also be shared with multiple agencies. 
TABLE 1. Primary City Transit Service Area Characteristics

\begin{tabular}{|c|c|c|c|c|c|c|}
\hline Primary City & Primary Transit Agency & $\begin{array}{l}\text { Service } \\
\text { Area } \\
\text { (sq. km) }\end{array}$ & $\begin{array}{l}\text { Service Area } \\
\text { Pop. } \\
\text { (Census 2010) }\end{array}$ & $\begin{array}{c}\text { Annual } \\
\text { Passenger km } \\
\text { per Capita }\end{array}$ & $\begin{array}{l}\text { Pop. Density } \\
\text { of Service } \\
\text { Area (sq. km) }\end{array}$ & $\begin{array}{l}\text { Fixed-Route Modes } \\
\text { (Annual Operating } \\
\text { Expenses, in millions) }\end{array}$ \\
\hline Atlanta, GA & $\begin{array}{l}\text { Metropolitan Atlanta Rapid } \\
\text { Transit Authority }\end{array}$ & 1,290 & $1,574,600$ & 1,150 & 1,221 & $\begin{array}{l}\text { Bus }(\$ 220), \text { Heavy Rail } \\
(\$ 208)\end{array}$ \\
\hline Austin, TX & $\begin{array}{c}\text { Capital Metropolitan } \\
\text { Transportation Authority }\end{array}$ & 1,352 & $1,023,135$ & 405 & 757 & $\begin{array}{c}\text { Bus (\$111), Hybrid Rail (\$14), } \\
\text { Commuter Bus (\$8) }\end{array}$ \\
\hline Dallas, TX & Dallas Area Rapid Transit & 1,803 & $2,423,480$ & 505 & 1,344 & Bus (\$249), Light Rail (\$151) \\
\hline Denver, CO & $\begin{array}{c}\text { Denver Regional } \\
\text { Transportation District }\end{array}$ & 6,024 & $2,619,000$ & 583 & 435 & Bus (\$313), Light Rail (\$87) \\
\hline Houston, TX & $\begin{array}{c}\text { Metropolitan Transit } \\
\text { Authority of Harris County }\end{array}$ & 3,328 & $3,527,625$ & 392 & 1,060 & $\begin{array}{c}\text { Bus (\$305), Commuter Bus } \\
(\$ 47), \text { Light Rail (\$18) }\end{array}$ \\
\hline Indianapolis, IN & $\begin{array}{l}\text { Indianapolis and Marion } \\
\text { County Public Transportation }\end{array}$ & 1,026 & 911,296 & 130 & 889 & Bus $(\$ 51)$ \\
\hline Los Angeles, CA & $\begin{array}{c}\text { Los Angeles County } \\
\text { Metropolitan Transportation } \\
\text { Authority }\end{array}$ & 3,919 & $8,626,817$ & 681 & 2,201 & $\begin{array}{c}\text { Bus (\$931), Heavy Rail } \\
\text { (\$117), Light Rail (\$234), } \\
\text { Bus Rapid Transit }(\$ 24)\end{array}$ \\
\hline Seattle, WA & King County Metro & 5,527 & $1,957,000$ & 763 & 354 & $\begin{array}{c}\text { Bus (\$440), Trolleybus }(\$ 61) \text {, } \\
\text { Street Car Rail }(\$ 3)\end{array}$ \\
\hline San Diego, CA & $\begin{array}{l}\text { San Diego Association of } \\
\text { Governments }\end{array}$ & 1,834 & $2,813,833$ & 355 & 1,534 & $\begin{array}{c}\text { Bus (\$143), Light Rail }(\$ 66) \text {, } \\
\text { Commuter Bus }(\$ 3)\end{array}$ \\
\hline
\end{tabular}

Source: Federal Transit Administration 2014

\section{Data: Description and Processing}

The EPA's new Access to Jobs and Workers via Transit database combines transit service and selected demographic variables to allow evaluation of the performance of neighborhoods in regard to their accessibility to destinations via public transit service (Ramsey and Bell 2014). This dataset includes information on a range of transit and population-related statistics, both at the US Census Bureau's Core Based Statistical Area (CBSA), which is a large metropolitan region, and block group geographies, which generally include multiple blocks, but smaller than most neighborhoods. CBSAs include one or more counties with a core area containing at least one core of 10,000 population or more, together with adjacent communities having a high degree of economic and social integration with that core (US Census Bureau 2012).

This study uses a small portion of the variables available related to transit access and income to evaluate equity across nine aforementioned large cities in United States. To evaluate relative equity of transit service, we focused on access to transit, using data related to the percentage of low-wage workers with transit access and the percentage of all workers with transit access. The first variable referring to transit accessibility is defined as the "employed population able to access the block group within a 45-minute transit commute from their home location as a percentage of total regional employed population" (Ramsey and Bell 2014, p. 4). The low-wage classification for the second attribute is defined as workers earning $\$ 1,250$ per month or less. The prevalence of 
low-wage workers in a block group is the focus in this study, but we also note that this statistic does not replace other key variables in understanding equity at the local level, such as the availability of jobs, and cultural relationships that may help support some low wage workers.

Transit service information includes calculations of travel time from each census block group to all other census block groups accessible via transit. Census 2010 data were integrated to tabulate how many people live and work in those accessible block groups, using a 45-minute travel time limit that includes wait times, transfers, and walking to and from transit stops. The 45-minute transit travel time restriction included with the EPA data source may not represent all trips well, since the 2009 National Household Travel Survey (NHTS) reports an average commute time of 53 minutes (Santos et al. 2011). This could be expected to restrict destination accessibility represented in these data more in suburban areas than city centers, but any bias in this regard is applied equally among the cities through these data. Each city's proportion of population living in urban and suburban areas varies, which is also affecting the efficiency of transit service. However, density variables predict less of the variability in transit use than diversity of land uses, street design, and distance to transit stops, on average (Ewing and Cervero 2010). The data cover only metropolitan regions and counties served by transit agencies that provide their service data using a standard data format called General Transit Feed Specification (GTFS), which includes stops, routes, trips, and other schedule data (Google 2012). Although sidewalk coverage is also related to increased transit use (Ewing and Cervero 2010), neither sidewalk quantity nor quality data are currently available for any of the cities in a comparable format.

\section{Methods}

This study demonstrates a method for analyzing spatial variation in transit access by income. Improvements to transit accessibility such as increases of geographic service and frequency are well-documented, but are restricted by funding available to transit agencies for improvements. This method contributes to evaluation of transit service at multiple scales, using publicly-available data described in the previous section. The next section describes our use of descriptive statistics and block group level geostatistics for identifying local variation, clusters and outliers in transit access.

\section{Descriptive Analysis}

We evaluated transit service equity by first understanding the level of accessibility experienced by low-income classification versus the accessibility level experienced by the remainder of the population, following EPA's Access to Jobs and Workers via Transit database definitions. For each block group in each of the nine CBSAs, equity was evaluated as the arithmetic difference between the percent of low-wage, transitaccessible workers and the total of transit-accessible workers. Next, we aggregated the differences in transit accessibility by income level at the CBSA level and calculated the average, minimum, maximum, and standard deviations of those differences. 


\section{Spatial Analysis}

In his article describing simulation of urban growth over time, Tobler invoked the first law of geography: "... everything is related to everything else, but near things are more related than distant things" (Tobler 1970). The degree to which each block group is influenced by its neighbor can be described with spatial statistics. Anselin developed a local Moran's I statistic to describe this relationship:

$$
I_{i}=z_{i} \Sigma_{j} w_{i j} z_{j}
$$

where "the observations $z_{i}, z_{j}$ are in deviations from the mean, and the summation over $j$ is such that only neighboring values $j \in J_{i}$ are included" (Anselin 1995). The local analysis of clustering of each block group with its neighbors prevents global statistics' tendency to hide issues of significance when averaged as a whole. Since we are interested in understanding the effects of transit service levels in different locations, the local Moran's I helps explain the likelihood of transit service being similar in locations close to each other.

Variances in transit access by income are expected to follow Tobler's Law, in that observations in one location are more likely influenced by their geographic neighbors than other locations. Therefore, local Moran's I is calculated using an inverse distance weighted conceptualization of spatial relationships. We used a Euclidean distance calculation on data with coordinates in the Albers equidistant geographic projection, which minimizes distortions in area and distance on a national scale. Like other local indicators of spatial autocorrelation, the local Moran's I "... gives an indication of the extent of significant spatial clustering of similar values around that observation" (Anselin 1995). Cluster and outlier analysis with Moran's I with the same transit service level datasets and income data across each of the regions allowed localized comparisons within each region, and between each other, in addition to $p$-values to evaluate statistical significance.

\section{Results}

Each of the nine large cities varies in the difference between workers' transit access by income class. Table 2 depicts the differences in transit service between low-wage and all transit-accessible workers in each of the nine study regions. Observed at the core based statistical area level, the Atlanta region has the least average difference between the percentage of low-wage workers and all transit-accessible workers, and the Austin region has the greatest discrepancy. Again, we define transit-accessible workers following the Access to Jobs and Workers via Transit database, as "employed population able to access the block group within a 45-minute transit commute from their home location as a percentage of total regional employed population" (Ramsey and Bell 2014).

The differences between the cities in terms of equity of transit service are significant ( $t=-3.954$, two-tailed $p=0.004)$ The minimum, maximum, and standard deviation indicate the lowest variation between block groups in the Atlanta region as well, with the greatest deviation in the Denver region. Though the Denver region provided the 
highest percentage of low-wage workers able to reach work destinations from their home location, it also had the highest standard deviation of block groups within the region, indicating disparity in local service. Such a regional view provides the first known analysis of these cities in terms of the income equity of transit service, helping answer questions of difference in transit accessibility between large cities and within neighborhoods.

TABLE 2.

Percent Difference in Transit Service between Low-Wage and All Transit-Accessible Workers

\begin{tabular}{|l|c|c|c|c|}
\hline \multicolumn{1}{|c|}{ CBSA } & $\begin{array}{c}\text { Average } \\
\text { Percent } \\
\text { Difference }\end{array}$ & $\begin{array}{c}\text { Minimum } \\
\text { Percent } \\
\text { Difference }\end{array}$ & $\begin{array}{c}\text { Maximum } \\
\text { Percent } \\
\text { Difference }\end{array}$ & $\begin{array}{c}\text { Standard } \\
\text { Deviation Percent } \\
\text { Difference }\end{array}$ \\
\hline Atlanta-Sandy Springs-Marietta, GA & -0.55 & -1.19 & 8.35 & 1.36 \\
\hline Los Angeles-Long Beach-Santa Ana, CA & -0.97 & -4.55 & 14.03 & 3.09 \\
\hline Dallas-Fort Worth-Arlington, TX & -1.11 & -2.29 & 10.69 & 1.74 \\
\hline San Diego-Carlsbad-San Marcos, CA & -1.27 & -6.19 & 22.68 & 4.97 \\
\hline Houston-Sugar Land-Baytown, TX & -1.61 & -3.60 & 13.32 & 2.83 \\
\hline Indianapolis-Carmel, IN & -2.16 & -5.47 & 15.75 & 4.70 \\
\hline Denver-Aurora-Broomfield, CO & -3.25 & -10.72 & 23.84 & 6.34 \\
\hline Seattle-Tacoma-Bellevue, WA & -4.41 & -8.23 & 24.40 & 5.25 \\
\hline Austin-Round Rock-San Marcos, TX & -5.80 & -10.04 & 11.82 & 5.95 \\
\hline
\end{tabular}

Transit equity can be evaluated at multiple geographic scales, and doing so reveals different results. The minimum percent difference of transit service by income in Table 2 refers to the individual block group in each region, with Atlanta again leading in terms of equity. However, there are local communities in the San Diego, Denver, and Seattle regions with a difference in the percent of population transit access by more than $20 \%$. The presence of rail transit in concert with fixed-route bus service is associated with the regions with the least variance in transit access by income class. This is likely due to the higher average speed associated with rail transit as compared to most bus transit, in addition to the larger overall transit investments of all modes found in Atlanta, Los Angeles, and Dallas. This snapshot of transit equity at the regional average and at the extremes in each region provides a first-level of screening analysis to help identify areas of concern. Future research would benefit from more detailed spatial analysis to determine where transit equity might need further review.

Analysis at the regional level reveals variances in access to transit service by income class, but these results must be reviewed with caution. Though the regions with the least apparent variance are well-served by at least fixed-route bus and rail transit, the location of low-income groups is not necessarily static, and transit agencies are challenged to coordinate their services in an efficient manner while serving the riders with the most need. However, global statistics can hide the relationships and clustering of transit access within and between neighborhoods, which is addressed by analysis of local spatial clustering.

Cluster and outlier analysis of local Moran's I unpacks the relationships between lowincome and all transit-accessible workers at the block group level. Each of the maps 
in Figure 1 displays this relationship classified into either clusters indicating similarity between block groups, or outliers indicating dissimilarity. Each grouping is significant $(p<0.05)$, or it is designated as Not Significant. Significant clusters of transit service levels and all income levels are indicated in green-high service in dark green, and low service in light green. The outliers are in purple-the darker area has the greatest discrepancy of transit service level by income, and the lighter shades indicate outliers with the least discrepancy in transit access by income.

FIGURE 1.

Transit service cluster and outlier analysis

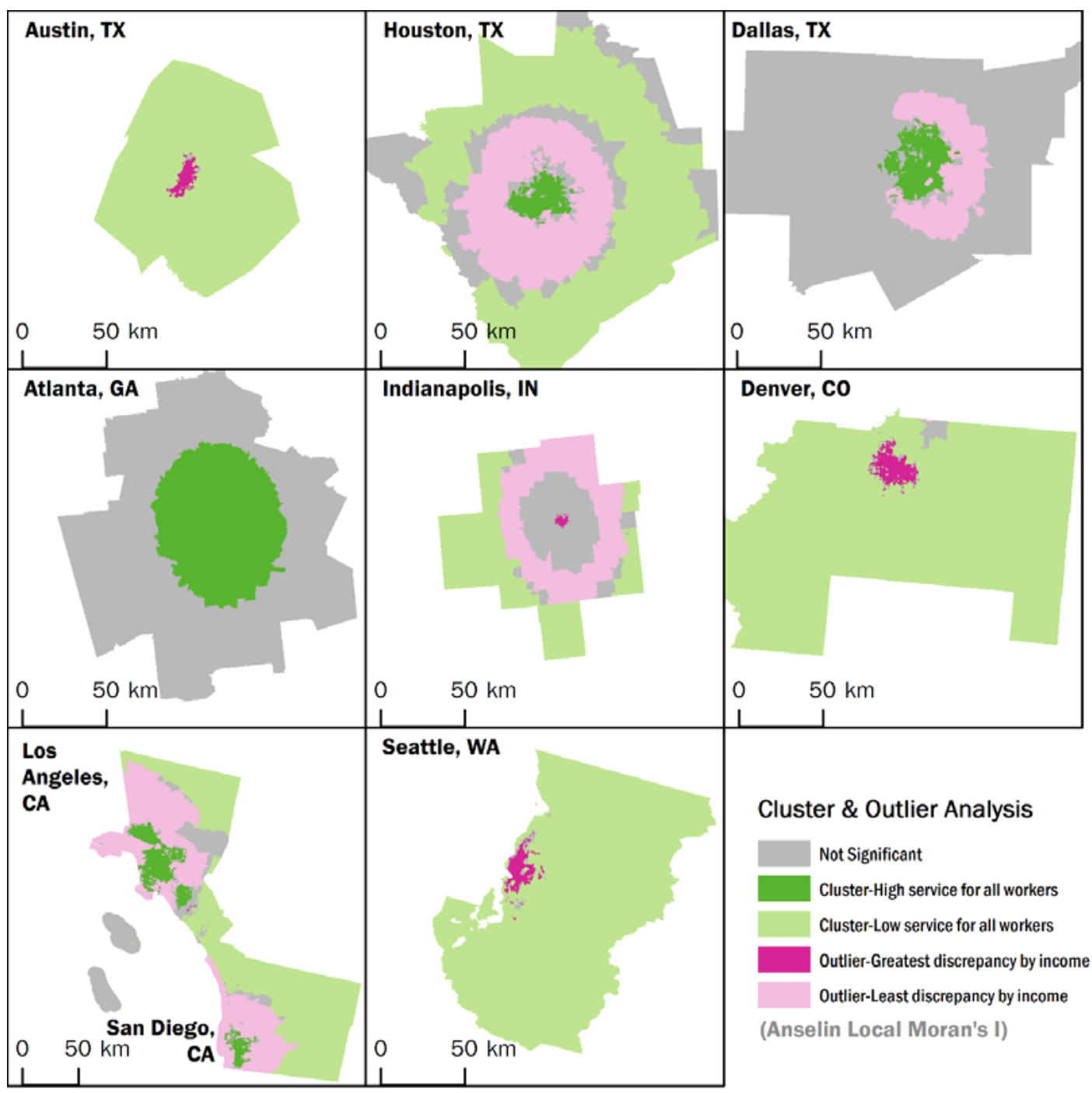

Regional analysis of spatial autocorrelation reveals neighborhood effects between transit access by income group. Each region reviewed is characterized by a different relationship between low income and all transit-accessible worker communities, but no region has a cluster of both low transit accessibility and low-income workers near its urban core. The radial patterns of the cluster and outlier analysis in Houston, Dallas, Atlanta, and, to a lesser degree, Indianapolis are partly due to the spatial pattern of the 
transit network, but may generally indicate that the transit services do not have major spatial omissions across the region. Conversely, Austin, Denver, and Seattle have large areas including their downtowns with a significant difference between transit access among low and all income groups. This finding aligns with local analysis, such as a recent case study of Denver's Southeast Light Rail Line, which demonstrated a growth in predominantly high-income jobs following completion of the service in 2006 (Sadler and Wampler 2013). In addition to the potential for transit service equity variance, this could be associated with constraints in the cost of service extensions, clustering of low-income neighborhoods, or other factors. Generally, Los Angeles and San Diego do not share the previous cities' spatial clustering of low and high transit access discrepancies by income at the neighborhood level.

The results of the cluster and outlier analysis in Figure 1 are consistent with the descriptive analysis in Table 2, identifying the greatest variation in transit access by income in the Austin, Denver, and Seattle regions and the least variation in Atlanta, Los Angeles, and Dallas. These differences can be due to a combination of factors relating to both transit services and the distribution of populations by income. Though all of these major cities receive Federal Transit Administration grants, each city deploys its own combination of local funding to support its system, which limits the comparability of systems with a singular method such as this one. The literature demonstrates that both of these issues are addressable by transportation and housing policies, planning, and implementation that seek to improve access to the supply of residential choices and mobility options that connect people of a range of incomes to jobs and services needed for a high quality of life. The methods described in this study could be useful for more in-depth, better-coordinated, and interactive policy analysis regarding transportation and housing, since cities in the US have varying governance and planning practices regarding transportation and housing.

\section{Conclusions}

Transit service changes in large, auto-oriented cities provide uneven access and mobility benefits, and, to date, US metropolitan planning organizations (MPOs) have accomplished little in terms of achieving spatial justice or social equity through transportation planning (Manaugh et al. 2015; Martens et al. 2012). Some cities, such as Los Angeles, rank highly in others' transit accessibility rankings (e.g., Owen and Levinson 2014), in addition to this study's analysis of equity by income. Other cities, such as Atlanta, may rank low on overall accessibility (e.g., Owen and Levinson 2014) while doing well in terms of equity by income. Additional methods are needed to leverage advanced data sources for more spatially disaggregate analysis of transit equity. Despite the recent emphases on performance measurement in federal guidance (Clinton 1994; United States Congress 2012), few spatial methods have been articulated to evaluate transportation equity. Confounding this challenge is the fact that changes in both transit provision and locations of low income demographic groups make equity analysis a moving target. The same challenges that affect travel demand modeling regarding demographics, mode choice, issues of temporal and spatial precision, and accuracy are 
present in similar quantitative analyses (Karner and Niemeier 2013). The application of recent advancements in spatial modeling, on the other hand, can help control for effects such as spatial autocorrelation, resulting in better understanding of the local nuances of transit service.

This study adds to the literature by employing a new data set integrating transit service, worker locations, and income, allowing standard comparisons of nine large cities as a whole, and a neighborhood scale as well. Regional summaries of differences in transit service for income classes provide a broad-scale analysis of income-based equity, while analysis of the same data with local Moran's I geostatistics provide a nuanced view of equity that controls for spatial autocorrelation. The method developed in this study is not aimed to be a substitute for local analysis including specific proposed transportation changes or land use effects, but can be considered a spatial screening tool to identify prospective equity issues at geographic areas larger than the more typical corridor analysis. The provision of transit modes beyond traditional bus service, such as rail, was found to have a positive relationship with transit equity at both the regional and neighborhood levels in this study. Increased numbers of routes and speeds may serve to increase mobility and access for all income levels, promoting job access, and in turn, economic mobility.

The methods used in this study point to policy and planning implications of not only the location of service, but speed and frequency having impacts on job access and economic mobility. To demonstrate competency in equitable service, planners and policy makers need standardized comparisons of locations that consider income. Transit investments represent a faith that allocation of projects serve existing and future needs, and efficient and accurate equity analyses support rational communication between the public and transit agencies if shared in open forums of discussion. This method can be adapted to scenario planning techniques by adjusting the transit service metrics by block group as an output of other planning processes involving public participation and modeling. Accessibility by income also could be used as input in comprehensive growth models for evaluation of policy and planning decisions.

In addition to growth in rail and bus transit, the increasing prevalence of bus rapid transit (BRT) may cause significant changes in transit accessibility, but this will be limited to the extent that low-income communities are conveniently served by this mode and its connectivity to destinations for these groups (Weinstock et al. 2011). In the cases that BRT can take advantage of managed lanes and other features designed to increase speed, it can reduce the time needed to reach more jobs within a reasonable time frame and can add job accessibility to the communities it serves. However, when transit services are added to improve mobility, retaining local access to the existing stops is crucial to many communities, including low-income neighborhoods.

After all of the preliminary analysis is done, the primary conduit for implementing transit policies and funding is through an urban area's transportation plan. The best analysis will likely be implemented when supported by robust public involvement with engaged public officials (Evans-Cowley and Griffin 2012; Slotterback 2010), and staff 
that work to explicitly incorporate social equity into the objectives and measures of transportation plans (Manaugh et al. 2015).

While examining the relationship between transit accessibility and worker income, this study does not address the root causes of discrepancies in this relationship. Future studies would benefit from adding to the literature in this area by integrating spatial analysis of urban form, housing affordability, other demographic variables associated with equity, and transit-based access to social services. The effect of multi-modal transit trips on accessibility and justice also need to be explored. Finally, future transit services could be modeled with local spatial analysis for equity using similar methods, which will help evaluate existing or proposed service levels to improve the equity of transit systems.

\section{Acknowledgments}

Research reported in this publication was in part supported by the National Institute of Diabetes and Digestive and Kidney Diseases of the National Institutes of Health under Award Number R01DK101593. The content is solely the responsibility of the authors and does not necessarily represent the official views of the National Institutes of Health. We also greatly appreciate the valuable insights of three anonymous reviewers on an earlier version of this paper.

\section{References}

Anselin, L. 1995. "Local Indicators of Spatial Association-LISA." Geographical Analysis, $27(2)$.

Appleyard, B., C. E. Ferrell, M. A. Carroll, and M. Taecker. 2014. "Toward Livability Ethics." Transportation Research Record, 2403: 62-71. doi:10.3141/2403-08.

Bailey, K., and T. Grossardt. 2009. "Toward Structured Public Involvement: Justice, Geography and Collaborative Geospatial/Geovisual Decision Support Systems." Annals of the Association of American Geographers, 100(1): 57-86. doi:10.1080/00045600903364259.

Beyazit, E. 2011. "Evaluating Social Justice in Transport: Lessons to be Learned from the Capability Approach." Transport Reviews, 31(1): 117-134. doi:10.1080/01441647.2010. 504900.

Boarnet, M. G. 2009. Transportation Infrastructure: The Challenges of Rebuilding America. Chicago: IL: American Planning Association. http://www.worldcat.org/ isbn/9781932364750.

Bond, A., and J. Kramer. 2010. "Governance of Metropolitan Planning Organizations. Transportation Research Record, 2174(-1): 19-24. doi:10.3141/2174-03.

Boschmann, E. E., M.-P. Kwan. 2010. “Metropolitan Area Job Accessibility and the Working Poor: Exploring Local Spatial Variations Of Geographic Context. Urban Geography, 31(4): 498-522. doi:10.2747/0272-3638.31.4.498. 
Bricka, S. G. 2008. "Trip Chaining: Linking the Influences and Implications." University of Texas.

Bullard, R. D. 2008. "Growing Smarter to Achieve Livable Communities and Regional Equity. Race, Poverty and the Environment, 15(2): 22-25.

Cambridge Systematics, Akin, Gump, Strauss, Hauer and Field, LLP. 2002. "Technical Methods to Support Analysis of Environmental Justice Issues." Washington, DC.

Capital Area Metropolitan Planning Organization. 2010. CAMPO 2035 Regional Transportation Plan. Austin, TX: Capital Area Metropolitan Planning Organization. www.campotexas.org.

Chmiliar, L. 2010. "Multiple-Case Designs." In A. J. Mills, G. Durepos, and E. Wiebe, eds., Encyclopedia of Case Study Research. Thousand Oaks, CA: SAGE Publications, Inc. doi:10.4135/9781412957397.

Christie, N., R. Kimberlee, E. Towner, S. Rodgers, H. Ward, J. Sleney, and R. Lyons. 2011. "Children Aged 9-14 Living in Disadvantaged Areas in England: Opportunities and Barriers for Cycling." Journal of Transport Geography, 19(4): 943-949. doi:10.1016/j. jtrangeo.2010.12.003.

Clark, W. A. V, and W. W. Wang. 2010. "The Automobile, Immigrants, and Poverty: Implications for Immigrant Earnings and Job Access." Urban Geography, 31(4): 523540. doi:10.2747/0272-3638.31.4.523.

Clinton, W. J. 1994. "Federal Actions to Address Environmental Justice in Minority Populations and Low-Income Populations." http://www.epa.gov/federalregister/eo/ eo12898.htm.

Delbosc, A., G. Currie. 2011. "Using Lorenz Curves to Assess Public Transport Equity." Journal of Transport Geography, 19(6): 1252-1259. doi:10.1016/j.jtrangeo.2011.02.008.

Duthie, J., K. Cervenka, and S. T. Waller. 2007. "Environmental Justice Analysis: Challenges for Metropolitan Transportation Planning." Transportation Research Record, 2013: 8-12. doi:10.3141/2013-02.

Duthie, J., and S. Waller. 2008. "Incorporating Environmental Justice Measures into Equilibrium-Based Network Design." Transportation Research Record, 2089: 58-65. doi:10.3141/2089-08.

Ehrenfeucht, R., and A. Loukaitou-Sideris. 2010. "Planning Urban Sidewalks: Infrastructure, Daily Life and Destinations." Journal of Urban Design, 15(4): 459-471. doi:10.1080/13574809.2010.502333.

Evans-Cowley, J. S., and G. Griffin. 2012. "Microparticipation with Social Media for Community Engagement in Transportation Planning." Transportation Research Record, 2307: 90-98. doi:10.3141/2307-10.

Ewing, R., and R. Cervero. 2010. "Travel and the Built Environment-A MetaAnalysis." Journal of the American Planning Association, 76(3): 265-294. doi:10.1080/01944361003766766. 
Fabish, L., and P. Haas. 2011. "Measuring the Performance of Livability Programs." Transportation Research Record, 2242: 45-54. doi:10.3141/2242-06.

Federal Transit Administration. 2014. National Transit Database. http://www. ntdprogram.gov/ntdprogram/data.htm.

Forkenbrock, D. J., and L. A. Schweitzer. 1999. "Environmental Justice in Transportation Planning." Journal of the American Planning Association, 65(1): 96-112. doi:10.1080/01944369908976036.

Forkenbrock, D. J., and J. Sheeley. 2004. "Effective Methods for Environmental Justice Assessment." NCHRP Report 532. Washington, DC: Transportation Research Board, National Research Council. http://trb.org/publications/nchrp/nchrp_rpt_532.pdf.

Foth, N., K. Manaugh, and A. M. El-Geneidy. 2013. "Towards Equitable Transit: Examining Transit Accessibility and Social Need in Toronto, Canada, 1996-2006." Journal of Transport Geography, 29: 1-10. doi:10.1016/j.jtrangeo.2012.12.008.

Golub, A., R. A. Marcantonio, and T. W. Sanchez. 2013. "Race, Space, and Struggles for Mobility: Transportation Impacts on African Americans in Oakland and the East Bay." Urban Geography, 34(5): 699-728. doi:10.1080/02723638.2013.778598.

Golub, A., G. Robinson, and B. Nee. 2013. "Making Accessibility Analyses Accessible: A Tool to Facilitate the Public Review of the Effects of Regional Transportation Plans on Accessibility." Journal of Transport and Land Use, 6(3): 17. doi:10.5198/jtlu. v6i3.352.

Golub, M. 2014. "Using Principles of Justice to Assess the Modal Equity of Regional Transportation Plans." Journal of Transport Geography. doi:10.1016/j. jtrangeo.2014.07.014.

Goodman, A., and J. Cheshire. 2014. "Inequalities in the London Bicycle Sharing System Revisited: Impacts of Extending the Scheme to Poorer Areas but then Doubling Prices." Journal of Transport Geography, 41: 272-279. doi:10.1016/j. jtrangeo.2014.04.004.

Google. 2012. "What is GTFS?" https://developers.google.com/transit/gtfs/.

Grengs, J. 2002. "Community-Based Planning as a Source of Political Change: The Transit Equity Movement of Los Angeles' Bus Riders Union." Journal of the American Planning Association. doi:10.1080/01944360208976263.

Griffin, G. P., and I. N. Sener. 2016. "Planning for Bike Share Connectivity to Rail Transit." Journal of Public Transportation, 19(2): 1-22. doi:10.5038/2375-0901.19.2.1.

Hanna, K. S. 2000. "The Paradox of Participation and the Hidden Role of Information: A Case Study." Journal of the American Planning Association, 66(4): 398-410. doi:10.1080/01944360008976123.

Hay, A. 1993. "Equity and Welfare in the Geography of Public Transport Provision." Journal of Transport Geography, 1: 95-101. doi:10.1016/0966-6923(93)90003-I. 
Jain, J., T. Line, and G. Lyons. 2011. "A Troublesome Transport Challenge? Working Round the School Run." Journal of Transport Geography, 19(6): 1608-1615. doi:10.1016/j. jtrangeo.2011.04.007.

Jiao, J., A. V. Moudon, and A. Drewnowski. 2011. “Grocery Shopping." Transportation Research Record, 2230: 85-95. doi:10.3141/2230-10.

Jones, P., and J. Evans. 2012. "The Spatial Transcript: Analysing Mobilities through Qualitative GIS.” Area, 44(1): 92-99. doi:10.1111/j.1475-4762.2011.01058.x.

Kaplan, S., D. Popoks, C. G. Prato, and A. Ceder. 2014. “Using Connectivity for Measuring Equity in Transit Provision." Journal of Transport Geography, 37: 82-92. doi:10.1016/j. jtrangeo.2014.04.016.

Karner, A., and D. Niemeier. 2013. "Civil Rights Guidance and Equity Analysis Methods for Regional Transportation Plans: A Critical Review of Literature and Practice." Journal of Transport Geography, 33: 126-134. doi:10.1016/j.jtrangeo.2013.09.017.

Litman, T. 2007. "Evaluating Transportation Equity." World Transport Policy and Practice, 8(2): 50-65.

Litman, T., and M. Brenman. 2012. "A New Social Equity Agenda for Sustainable Transportation." Transportation Research Board Annual Meeting, Washington DC. http://www.vtpi.org/equityagenda.pdf/nhttp://citeseerx.ist.psu.edu/viewdoc/ download?doi=10.1.1.227.9699andrep=rep1andtype $=$ pdf.

Lucas, K. 2012. "Transport and Social Exclusion: Where Are We Now?" Transport Policy, 20: 105-113. doi:10.1016/j.tranpol.2012.01.013.

Manaugh, K., M. G. Badami, and A. M. El-Geneidy. 2015. “Integrating Social Equity into Urban Transportation Planning: A Critical Evaluation of Equity Objectives and Measures in Transportation Plans in North America." Transport Policy, 37: 167-176. doi:10.1016/j.tranpol.2014.09.013.

Martens, K., A. Golub, and G. Robinson. 2012. "A Justice-Theoretic Approach to the Distribution of Transportation Benefits: Implications for Transportation Planning Practice in the United States." Transportation Research Part A: Policy and Practice, 46(4): 684-695. doi:10.1016/j.tra.2012.01.004.

McCray, T. 2009. "Engaging Disadvantaged Populations in Transport Studies: Linking Modal Use and Perceptions of Safety to Activity Patterns." Research in Transportation Economics, 25(1): 3-7. doi:10.1016/j.retrec.2009.08.002.

McCray, T., and N. Brais. 2007. "Exploring the Role of Transportation in Fostering Social Exclusion: The Use of GIS to Support Qualitative Data." Networks and Spatial Economics, 7(4): 397-412. doi:10.1007/s11067-007-9031-x.

Owen, A., and D. Levinson. 2014. Access Across America: Transit 2014. Minneapolis, MN.

Phillips, C. G., and H. R. Edwards. 2002. "Approach for Developing Integrated Mass Transit Systems Application to City of Baltimore, Maryland." Transportation Research Record, 1793: 71-79. 
Plotnick, R. D., J. Romich, J. Thacker, and M. Dunbar. 2011. "A Geography-Specific Approach to Estimating the Distributional Impact of Highway Tolls: An Application to the Puget Sound Region of Washington State." Journal of Urban Affairs, 33(3): 345-366. doi:10.1111/j.1467-9906.2011.00551.x.

Pucher, J. 2004. "Public Transportation.” In S. Hanson and G. Giuliano, eds., The Geography of Urban Transportation. New York: The Guilford Press.

Ramani, T., J. Zietsman, H. Gudmundsson, R. Hall, and G. Marsden. 2011. "Framework for Sustainability Assessment by Transportation Agencies." Transportation Research Record, 2242: 9-18. doi:10.3141/2242-02.

Ramsey, K., and A. Bell. 2014. "Access to Jobs and Workers via Transit." Washington, DC: U.S. EPA Office of Sustainable Communities. https://edg.epa.gov/data/Public/OP/ SLD/SLD_Trans45_UG.pdf.

Sadler, B., and E. Wampler. 2013. "Enhancing Economic Opportunity through Transit: Lessons Learned from Denver's Southeast Light Rail Line." http://www. reconnectingamerica.org/resource-center/books-and-reports/2013/enhancingeconomic-opportunity-through-transit-lessons-learned-from-denver-s-southeastlight-rail-line/.

Sanchez, T., R. Stolz, and J. Ma. 2004. "Inequitable Effects of Transportation Policies on Minorities." Transportation Research Record, 1885: 104-110. doi:10.3141/1885-15.

Santos, A., N. McGuckin, H. Y. Nakamoto, D. Gray, and S. Liss. 2011. "Summary of Travel Trends: 2009 National Household Travel Survey." Washington, DC: U.S. Department of Transportation Federal Highway Administration.

Schlossberg, M. A. 2001. "Coordinating Community-Based Paratransit in an Era of Devolution: A Role for the State." University of Michigan. http://gateway. proquest.com/openurl?url_ver=Z39.88-2004andrft_val_fmt=info:ofi/ fmt:kev:mtx:dissertationandres_dat=xri:pqdissandrft_dat=xri:pqdiss:3016955.

Slotterback, C. S. 2010. "Public Involvement in Transportation Project Planning and Design." Journal of Architectural and Planning Research, 27(2): 144-162.

Tobler, W. R. 1970. "A Computer Movie Simulating Urban Growth in the Detroit Region." Economic Geography, 46: 234-240.

Ungemah, D. 2007. "This Land Is Your Land, This Land Is My Land: Addressing Equity and Fairness in Tolling and Pricing." Transportation Research Record, 2013: 13-20. doi:10.3141/2013-03.

United States Congress. Moving Ahead for Progress in the 21st Century Act (MAP-21). Pub. L. No. 112-141 (2012).

United States Department of Justice. 1964. Title VI of the 1964 Civil Rights Act. http:// www.justice.gov/crt/about/cor/coord/titlevistat.php.

United States Department of Transportation. 2012. Department of Transportation Updated Environmental Justice Order 5610.2(a). http://www.fhwa.dot.gov/ environment/environmental_justice/ej_at_dot/order_56102a/. 
US Census Bureau. 2012. "2010 Geographic Terms and Concepts-Core Based Statistical Areas and Related Statistical Areas." http://www.census.gov/geo/reference/gtc/ gtc_cbsa.html.

Weinstock, A., W. Hook, M. Replogle, and R. Cruz. 2011. Recapturing Global Leadership in Bus Rapid Transit. New York.

Welch, T. F., and S. Mishra. 2013. "A Measure of Equity for Public Transit Connectivity." Journal of Transport Geography, 33: 29-41. doi:10.1016/j.jtrangeo.2013.09.007.

\section{About the Authors}

Greg Phillip Griffin, AICP (g-griffin@tti.tamu.edu) is a Ph.D. student in Community and Regional Planning at The University of Texas at Austin and a researcher in the Austin office of the Texas A\&M Transportation Institute (TTI). His research explores planning theory and practice, health and active transportation, and the role of collaborative technologies in each.

IPek Nese Sener, Ph.D. (i-sener@tti.tamu.edu) is a researcher in the Austin office of TTI. Her research focuses mainly on travel demand modeling and travel behavior analysis. She has a particular interest in transportation-based health research, promoting sustainable environments, and studying the health outcomes of transportation systems, the built and travel environment, and individuals' activity-travel behavior. 